\title{
Crossing the Threshold in Introductory Women's and Gender Studies Courses: An Assessment of Student Learning
}

ABSTRACT

This article reports on a scholarship of teaching and learning (SoTL) project in the introductory women's and gender studies course, occasioned by a curricular redesign to focus the course on four threshold concepts within the field: the social construction of gender, privilege and oppression, intersectionality, and feminist praxis. The authors identify the metaphors students used to describe their learning, focus on the roles of metacognitive development and affective learning, and discuss the most difficult course concept for students: intersectionality.

\section{KEYWORDS}

SoTL, women's and gender studies, social construction of gender, intersectionality, privilege and oppression, feminist praxis, student learning outcomes

As long-time faculty members of the UW System-a coalition of women's and gender studies (WGS) program directors and department chairs from across the state-we have organized and participated in many conversations and workshops focused on teaching the introductory Women's and Gender Studies course, and more specifically, on what we hope students learn in the course. Because of our close connections as transfer institutions and our shared interests in WGS, conversations productively turned toward what key ideas, skills, and knowledge students in this critical class should cultivate before moving on to more advanced coursework.

Starting in 2010, these workshops and conversations came to focus on the identification of threshold concepts of the course, and of the field of Women's and Gender Studies more generally. The term "threshold concept" was coined by educational theorists Ray Land and Jan Meyer (2005) in order to distinguish between "core learning outcomes that represent 'seeing things in a new way' and those that do not" (p. xv). According to Land and Meyer, threshold concepts "can be considered as akin to a portal, opening up a new and previously inaccessible way of thinking” (p. xv). Crossing a threshold of understanding, then, affords a student "a transformed way of understanding, or interpreting, or viewing something” (p. xv). Land and Meyer also argue that a student's learning within a field cannot progress until they have crossed the threshold. Their work, along with that of David Perkins, has also focused on the "troublesome" nature of some threshold concepts, in that transformed understanding and new ways of thinking entail "a letting go of earlier, comfortable positions and encountering less familiar and sometimes disconcerting new territory” ( $\mathrm{p} . \mathrm{xv})$.

Meyer and Land's work on threshold concepts has been generative in many disciplines across the humanities, social sciences, and natural sciences; indeed, Land, Rattray, and Vivian (2014) note that 
The threshold concepts approach to student learning and curriculum design now draws from an empirical research base comprising hundreds of academic papers from over 120 disciplinary and professional contexts, and from authors in the higher education sectors of many countries ( $p$. 200)

ranging from writing studies to information literacy to higher education and beyond (see Adler-Kassner \& Wardle, 2015; Hofer, Townsend \& Brunetti, 2012; Humphrey \& Simpson, 2012). Pace and Middendorf's 2004 Decoding the Disciplines began some of the work of defining threshold concepts within the academic disciplines in a range of liberal arts fields, and building on this foundation, we believe that it is especially useful for thinking about student learning in Women's and Gender Studies, especially the introductory course, in which students grapple-many for the first time-with the core premises of our field. In particular, the idea that knowledge in Women's and Gender Studies courses can be 'troublesome' rings true to our experience of teaching and provides a useful framework for thinking about what and how students learn. Much of the material in introductory Women's and Gender Studies courses asks students to re-think 'common sense' ideas and assumptions about their culture, their society and how it works, and their experiences, including their experiences of their own bodies. This process can be both alienating and affirming.

Over time and through much deliberation, the co-authors identified four threshold concepts in Women's and Gender Studies ${ }^{1}$ : the social construction of gender, privilege and oppression, intersectionality, and feminist praxis, ${ }^{2}$ recognizing their interconnectedness as well as the ways that related ideas could lay equal claim to their prominence in the field and in the learning goals of the course.

As we engaged in the work of identifying these threshold concepts, we simultaneously came to two related realizations:

1) the majority of introductory women's and gender studies textbooks were not organized in a way that made it easy to foreground these concepts throughout the Intro course ${ }^{3}$; and

2) our own courses replicated this backgrounding of the threshold concepts in favor of content coverage.

Both of us certainly introduced all four of these concepts in our courses, but in a way that foregrounded the key issues and institutions that provided the structure for the bulk of the course-for example, discussing and introducing what we are now calling threshold concepts at the beginning of the semester before moving on to 'content-focused' units on paid and unpaid work, dating and marriage, family, parenting, and gendered violence. As a result, when we would ask students to reflect on their learning at the end of the course, we were often disappointed to find that, while students came away from our courses with concrete knowledge about, for example, rates of gendered violence in the U.S., family leave policies, or the gendered wage gap, they often lacked a deeper understanding of how those statistics emanated from intersecting systems of privilege and oppression. And even when students seemed to understand the connection, it was in an intuitive and tacit way, rather than that connection being consistently explicit in their written work. Land, Rattray, and Vivian's assertion that "The teacher's leaving 'tacit' components of knowledge crucial to student understanding, has been found to be a frequent source of 'conceptual bottlenecks' for students" (2014, p. 13) rings true with our teaching experience.

As a result of these realizations, we both significantly restructured our courses around these four threshold concepts, integrating them with some of the critical elements of feminist pedagogy such as an emphasis on engaged practice and the goal of integrating personal and academic learning, but refocused 
away from 'content knowledge.' In practice, this meant taking our topical course content and reframing it in relation to the threshold concepts, with the intention of adopting what Lendol Calder calls an "uncoverage" model, one in which students learn to think, see, and know like feminist scholars rather than absorb a body of disciplinary knowledge to be "covered" (Calder, 2006). Logistically speaking, the four threshold concepts are introduced in depth one at a time over the course of the semester, though all four are foreshadowed and referenced from the beginning. Overall, our intent is to help students learn those ways of seeing, thinking, and knowing and then to be able to apply them to new subjects, in the way that feminist scholars do. In this article, we report on the results of a scholarship of teaching and learning project in which we posed several research questions focused on examining the effects of this curricular redesign with the aim of documenting how and whether students 'cross the threshold' on these concepts as well as mapping the roadblocks and learning bottlenecks that students encounter in the introductory WGS course.

\section{BACKGROUND}

In the Introduction to Opening Lines: Approaches to the Scholarship of Teaching and Learning (2000), editor Pat Hutchings describes a taxonomy of four questions that guide the scholarship of teaching and learning. Most relevant to our study is the "what is" question — that is, a question that aims to 'take stock,' document or map out an area of teaching and learning in a systematic way. Our project, then, is not so much driven by the question of "what works?"; that is, we are not "seeking evidence about the relative effectiveness of different approaches," (p. 4) rather by the question of what student learning looks like using a threshold concepts approach to the introductory women's and gender studies course.

More specifically, our research questions were not framed in terms of comparisons with a control section, or even in any direct way with past approaches beyond continuing to incorporate some key practices like reflective writing and a focus on the societal institutions typically examined in WGS courses such as work, religion, the law, the family, etc. In terms of how this project evolved, we had already convinced ourselves of the value of a threshold concepts approach and committed to the process of developing new syllabi, course materials, and assignments prior to making the decision to design this SoTL project. Indeed, it was not until the immediate lead-up to piloting the new version of the course that we had a 'eureka' moment about setting up this project. In our eagerness to dive into (and immerse ourselves in) the new approach, we were loath to run a section or sections of the course that didn't use the threshold concepts approach, and instead decided to take a "what is?" rather than a "what works?" approach to the SoTL project. Overall, we are primarily interested in mapping out the learning experience in relation to the curriculum rather than comparing it in empirical ways to prior offerings or other approaches.

Our primary research question is how/does a curriculum focused on threshold concepts in Women's and Gender Studies help students 'cross the threshold' into the field?, though through the course of our analysis of student work, the primary focus became "How does," with the presumption that the curriculum did/does work, and works in a particular fashion that we hoped to unpack and document. We also posed several follow-up questions that captured the learning goals we hoped to understand more fully:

2. What barriers, misconceptions, or learning roadblocks do students experience to grasping the four threshold concepts identified?;

3. How does students' prior knowledge/learning affect their ability to grasp the four threshold concepts (social constructionism, privilege and oppression, intersectionality, and feminist praxis)?; and 
4. What pedagogical strategies, instructional methods, readings, or other classroom activities are most effective in "unlocking" the concepts for students?

For the purposes of this essay, we focus primarily on questions two and three-what observations we made about student learning over the course of the semester, using the threshold concepts approach, and identifying the learning roadblocks that kept some students from achieving the course outcomes. We also address the fourth question, though more indirectly, by discussing specific aspects of the course that were instrumental in supporting student learning. We sought and received IRB approval to collect data during the Fall 2014 semester from our respective sections of Introduction to Women's and Gender Studies at two different institutions within the UW system.

We have found that there is a dearth of published SoTL work in the field of WGS, ${ }^{4}$ though teaching and learning have been of great interest to practitioners in the field since its founding in the early 1970s. The 2012 co-authored chapter A Signature Feminist Pedagogy: Connection and Transformation in Women's Studies, in the anthology Exploring More Signature Pedagogies, notes that

... the Scholarship of Teaching and Learning (SoTL) literature in Women's Studies-work that qualitatively or quantitatively measures the impact of teaching and the assessment of student learning-is still developing. The majority of feminist pedagogy literature continues to focus on the "what we do" and "what we should do" best practices (p. 147).

While we certainly value teacher reflections, narratives, and descriptions as well as case studies, we are hungry for published studies of student learning in WGS courses that are "RAD," to use Rich Haswell's acronym: replicable, aggregable, and data-driven (Haswell, 2005). Traditionally, feminist pedagogical scholarship has drawn from a cross-disciplinary range of techniques ranging from historical analysis, theorizing, synthesizing sources, reflection, narration, description, and argument. The mixedmethod analysis we propose here takes a fairly standard approach to an SoTL project as Peter Felten describes it, a project that follows his defined "Principles of Good Practice in SoTL": inquiry focused on student learning, grounded in context, methodologically sound, conducted in partnership with students, appropriately public (p. 122). Or in other words, as Holly Hassel (2013) asserts in Looking at Learning Systematically, "inquiry that is guided by a research question, undertakes a systematic method of study, and results in disseminated conclusions" (p. 57).

Lastly, we are also motivated by our belief in the threshold concepts approach to course structure and assessment; through publishing our findings, we hope to stimulate conversation about the concepts we have identified as thresholds in the field, with the idea that others may take up, expand, and/or revise our framework. Our textbook (Launius \& Hassel, 2015) offers four threshold concepts in women's and gender studies-however, other disciplines have undertaken work that is much more expansive, such as the writing studies collection Naming What We Know: Threshold Concepts of Writing Studies (Adler-Kassner \& Wardle, 2015) which offers no fewer than 37 such concepts. ${ }^{5}$ We hope that the present analysis is a starting point for additional disciplinary conversation about what the critical concepts are in the field. Moreover, what the present study aims to do is to develop a firmer assessment of several key aspects of helping students develop a command of a feminist epistemology that the identified threshold concepts reflect. Essentially, this project will be a starting point to 'map out,' confirm, or complicate those learning roadblocks that students experience as well as what texts, classroom activities, instructional activities, and assignments can best intervene in those roadblocks. 


\section{METHODOLOGY AND ANALYSIS}

In order to answer our research questions, we collected five pieces of written work from each student over the course of the semester. ${ }^{6}$ Students were provided with an overview of the project and an informed consent form that they were able to bring home and then return the following class period; forms were collected and held in a secure location without review by the instructors. After submission of grades, the investigator-instructors reviewed the consent forms and sorted students into participating and non-participating groups. Only participating students' work was included in the analysis phase of the project.

During the first week of the semester, we distributed a survey to students asking about any prior learning about the course concepts, their current understanding of threshold concepts, as well as their reasons for signing up for the course, and what they expected to learn (Appendix A). A follow-up survey was distributed during the final week of the semester; this survey again asked students about their current understanding of the threshold concepts, whether their expectations for learning had been met, and whether they had encountered the course concepts in any of their other courses during the semester (Appendix B). We also collected two written assignments called 'skills assessments,' in which students responded to a prompt that asked them to synthesize what they had learned in class by using the threshold concepts as lenses through which to analyze text(s). The first of these was a timed writing that focused on the social construction of gender and asked students to analyze a television advertisement (they chose between a Summer's Eve and an Axe Body Spray commercial), while the second was a takehome essay about work-life issues that focused on the first three threshold concepts (the social construction of gender, privilege and oppression, and intersectionality) (Appendix C).

We also collected their final reflective essays, written at the end of the semester, in which the students reflected on their learning process (Appendix D). It is important to note for the purposes of our later analysis that this type of reflective writing is a staple of feminist pedagogy that is characteristic of WGS courses; we had both previously used such assignments, usually at the end of the semester in order to assess learning outcomes usual to our programs such as 'Apply course concepts to their own lives', 'Relate learning in the classroom to lives in communities', 'Integrate knowledge and experience', and 'Develop gender consciousness.' At the national level, Amy Levin's Questions for a New Century: Women's Studies and Integrative Learning, a special report to the National Women's Studies Association on assessment, identifies "Engaging in critical self-reflection, promoting self-awareness" as one of many "Common Learning Outcomes for Women's Studies" (Levin, 2007, p. 17). As a standard learning goal in women's and gender studies, we distinguish between the learning demonstrated via the threshold concepts approach and the visibility of student learning that is inherent to reflective assignments.

After determining which students had given consent to participate in the study, we created a spreadsheet listing all of the students in alphabetical order. We read through all five pieces of writing by each student together. ${ }^{7}$ The skills assessments were assessed using a rubric (Appendix E) that evaluated whether students were advanced, proficient, competent, or developing in their work (based on the criteria of framing and analysis, evidence, and accuracy of understanding). We traced and analyzed how students progressed over the course of the semester, analyzing which students, according to our rubric, had, to the degree that it is possible to assess, 'crossed the threshold' on a particular concept at each point of assessment during the semester. We made written comments about all five pieces of writing, and jointly determined whether each student had crossed the threshold. As a part of this process, we began identifying themes. Once we noticed a theme, we wrote it down, kept a running list of the names of students whose work contained the theme, and included quotes from those students' writing. Once we 
had read and assessed all of the students' work, we revisited the themes we had identified and re-read the texts of the students whose names were on the list.

In the sections that follow, we offer several conclusions. First, we discuss some of the conclusions we drew in answer to our first research question: how did this curricular approach help students cross the threshold? Second, we describe what we saw as patterns in learning roadblocks or bottlenecks that students faced in approaching each concept and trends across the sequence of them.

\section{CROSSING THE THRESHOLD: WAYS OF SEEING}

We observed three trends in participating students' performance over the course of the project. First, students frequently invoked the language of 'seeing,' or metaphors for their learning that relied on a new vision of the material. Second, the threshold concepts approach both invited and supported metacognitive learning. Third, the threshold concepts approach encouraged students to do integrative and affective learning in which they built on prior knowledge to integrate their previous understanding into their new learning. We acknowledge that it isn't always possible, particularly with a course focused so clearly and directly on metacognition, consciousness-raising, and praxis, to definitively separate those elements of the threshold concepts that led to these findings. In this section, we attempt to distinguish between and acknowledge those aspects of the course that we see as directly tied to the threshold concepts approach and those that are rooted in metacognitive pedagogies and curricula.

Throughout the semester, we presented the threshold concepts in terms of ways of seeing, thinking, and knowing. In other words, we were very clear with students that the threshold concepts did not just represent a set of terms to memorize, but rather that learning the concepts entailed an epistemological shift that would be slow and take place over time. We were gratified, then, to see that many students had internalized and adopted this framework by incorporating it thoughtfully into their reflective writing at the end of the semester. Through specific metaphors, students articulated their transformed and troubled understanding. Vision-related metaphors were ubiquitous; we documented 15 of 30 students (50\%) using the language of "seeing," "looking" or "opening eyes" to describe their learning in the course. This is reflected in student comments like "I'm able to see how a feminist views topics" and "I started seeing more and more gender issues that I didn't even realize were issues before." Another way of framing 'learning as seeing' was explained by a student as "I look at gender and gender issues a lot deeper now, I am a lot more aware of all the issues that involve gender now." The phrasing of having his or her 'eyes opened' was applied to a wide range of topics in the course, from "this semester really opened my eyes to what feminism is" to "I have had my eyes opened to a new way of looking at certain issues" to "my eyes have opened to see and notice how society affects/decides how we act."

Students frequently included examples to further elaborate on specific instances in which they now see things differently. For example, one student wrote,

This course has taught me that the social construction of gender is something that we see every day, but we don't always realize what it is. I now know how to recognize this, and will do what I can to tell those who break these so-called gender norms that it is perfectly fine for them to express themselves in any way that they want. That is for sure a message that I would love to pass on to my future children.

Another student who asserted that the course made her look at the world differently gave the example of noticing "the lack [of] or sexualization of women. It's funny how things you see every day are portrayed when you know more information.” 
Statements like these resonate clearly with Meyer and Land's assertion that crossing a threshold within an academic field allows learners to access a "new and previously inaccessible way of thinking about something" (Meyer \& Land, 2005, p. 4). As Hassel and Nelson observe in their synthesis of the signature pedagogy of women's and gender studies,

\section{instructors [using feminist pedagogy] routinely employ pedagogical techniques that invite students to think like feminist scholars....in the classroom, then, this might take the form of gender moments journals...or reflective narratives that ask students to discuss their own experiences as gendered beings and connect those experiences with course content (2012, p.153).}

Reflective activities are essential components of women's and gender studies courses, but the distinctive feature of this project is the metaphors of seeing that pervaded student work, a metaphor we attribute to the threshold concepts focus on 'ways of seeing, thinking, and knowing.'

A second important pattern of learning that our analysis exposed, and that is related to the first, was the visibility of learning that a threshold concepts approach offers. Adopting the threshold concepts approach to the introductory course meant that we consistently presented the concepts as analytical lenses through which to approach the content. For example, when presenting content about gender violence, a concerted effort was made to explicitly contrast what gender violence looks like when approached using the threshold concepts as opposed to using another type of analytical lens. Rebecca Solnit's essay, A Rape a Minute, a Thousand Corpses a Year (2013), which was an assigned reading in the course, serves to support this approach to the topic. The idea here is to emphasize what comes into focus when exploring the issue of gender violence using the threshold concepts approach, in terms of explaining what gender violence is, what its sources are, what perpetuates it and why, and what we might do to tackle it as a social problem, including how the concepts of social constructionism, privilege and oppression, intersectionality, and feminist praxis are inflected individually and collectively in that issue.

We believe that the threshold concepts approach that we adopted, with its emphasis on using the concepts as lenses, provides critical additional and different opportunities for students to not just practice the metacognitive and reflective elements inherent to feminist pedagogy but also gives them more discipline-specific language to articulate their learning. This concurs with research by Susan Ambrose, et al., that traces the importance for learners of moving from the spectrum of unconscious incompetence to conscious competence as cognitive growth necessary for grappling with complex content. As Ambrose, et al., observe: as students gain knowledge "they are increasingly aware of what they do not know and, consequently, of what they need to learn," an important developmental stage that is required for students to move to conscious competence, where they have "considerable competence...yet still must think and act deliberately and consciously" (2010, p. 97). Over half of our student participants commented in their writing on this movement, with 16 of 30 students (53\%) explicitly addressing a lack of prior knowledge that the course either exposed or changed.

Some representative student comments include student references to their prior lack of understanding which had been made visible by a new way of 'viewing' a text, problem, or even the field of WGS: "After watching the commercial advertising Summer's Eve products, titled 'Hail to the V' I noticed things that I never really thought twice about before taking this class" and a second student remarking "I thought I knew what being a feminist was, but I may not." Some students applied this framework of "old/new ways of thinking" to specific threshold concepts, like one student's observation about the way prior knowledge or commonsense understandings had shaped her understanding of the concept of 
privilege and oppression: "In my point of view, privilege was a good thing in my mind until I really learned about it and thought about the people who are on the short end of the stick." According to students, readings that were particularly instrumental in this learning (and in learning about white privilege in particular) included readings by Peggy McIntosh and Tim Wise, as well as a short video clip from a documentary called Cracking the Codes: Understanding the System of Inequity, that features Joy Degruy telling a story that illustrates how racial oppression of people of color and white privilege are two sides of the same coin.

Another student acknowledged growth from the beginning to the end of the semester, admitting a sense of new understanding and awareness that her previous knowledge was not as extensive as she thought: "I thought I knew what most of these issues were already but as we were introduced to the four threshold concepts I realized, I knew very little." The final reflective essay assignment gave students a venue for mapping out (and sometimes self-flagellating about) their prior lack of exposure and how the course had both made them aware of something they had previously given little thought to, and allowed them to fill in gaps in their knowledge:

When I first signed up for this class I had never thought about feminism and the equality of the sexes very much. I always thought that there was already equality and I never had a deeper understanding of feminism. I was just like the bad people we read about in chapter 2 , that feminists were just lesbians that hated men. I was never taught any better until now.

The threshold concepts approach foregrounds the process of learning and makes it an explicit part of the experience of the course, but it also lays bare and articulates to students how the concepts as lenses can illuminate content. In addition, returning to the same content through multiple lenses enhanced students' abilities to use metacognitive language and visibility metaphors in specific ways. Analyzing those essays provides insights into students' learning and their awareness of that learning.

Finally, nearly half of the participating students repeatedly used language in their assessments that suggested students who crossed the threshold were more likely to demonstrate affective learning, in which they integrated personal experience and prior knowledge with new understanding, culminating in a new understanding of praxis/action. Because they are intertwined in some ways, we need to briefly unpack the distinction between 'knowing' the threshold concept of 'feminist praxis,' and 'doing' feminist praxis. For the purposes of the course, we gauged whether a student had crossed the threshold through their demonstrated ability to understand, explain, and identify feminist praxis. The many examples in the text we used for the course that involve, for example, bystander intervention or online activism, are ways of manifesting feminist consciousness resulting in action-but in terms of assessing students' grasp of the idea, most of which would be demonstrated in sites outside the classroom, we measured students' attainment of this concept by how accurately they described it and were able to identify examples of praxis. In this way, students' assertions about specific ways they would 'enact' a feminist consciousness are evidence of understanding the concept even if the course design stops short of actually assessing student enactment of feminist praxis.

Most interesting to us about our study of how this threshold concept was realized by students is the relationship between students' affective learning specifically in the context of feminist praxis. 14 of the 30 students (47\%) articulated a desire to act on their knowledge, positioning their academic learning within the context of previous behavior and belief, usually combined with an emotional stance of commitment (for example, empathy, optimism and regret, sadness, enthusiasm). To illustrate, the final learning survey prompted students to make comments asserting a commitment to change: "After taking 
this class I plan to use what I have learned to make changes in my own life, and hopefully help others do the same" and "One of the most distinct changes caused by this class is that I have no hesitation defining myself as a feminist." Common patterns were what we characterized as student 'pledges' to act differently or in activist ways in their future: "I hope to see a path to progress regarding these problems in the near future and thanks to this class, I, in a very small way, will be a part of that path"; "I have a different perspective and opinion on how to handle situation and want to help make a change"; "It taught me that this world is pretty messed up, but we- I-can help fix it," were three student pledges, for example. These statements added to our ability to assess students' understanding of feminist praxis in that the demonstration of what feminist praxis is was coupled with an insight into the emotional impact of that learning.

In addition to the qualitative and textual analysis we did, we also assessed each student's achievement of the threshold concepts at each point in the semester, to the degree that each of the concepts could be assessed by that activity:

Table 1. Assessment of student work by threshold concept and percentage of students who were assessed as "crossing the threshold" at each point in the semester.

\begin{tabular}{|l|l|l|l|l|l|}
\hline & $\begin{array}{l}\text { Week 1 Survey } \\
(\mathrm{n}=34)\end{array}$ & SA1 & SA2 & Reflective essay & $\begin{array}{l}\text { Week 15 Survey } \\
(\mathrm{n}=30)\end{array}$ \\
\hline $\begin{array}{l}\text { Social } \\
\text { Construction of } \\
\text { Gender }\end{array}$ & $\begin{array}{l}10 \\
(29 \%)\end{array}$ & $26 / 32 \quad(81 \%)$ & $27 / 30(90 \%)$ & $27 / 30(90 \%)$ & $\begin{array}{l}21 \\
(70 \%)\end{array}$ \\
\hline $\begin{array}{l}\text { Privilege and } \\
\text { Oppression }\end{array}$ & $\begin{array}{l}9 \\
(26 \%)\end{array}$ & NA & $21 / 30(70 \%)$ & $27 / 30(90 \%)$ & $\begin{array}{l}21 \\
(72 \%)\end{array}$ \\
\hline Intersectionality & $\begin{array}{l}1 \\
(3 \%)\end{array}$ & NA & $21 / 30(70 \%)$ & $25 / 30(83 \%)$ & $\begin{array}{l}7 \\
(24 \%)\end{array}$ \\
\hline Feminist Praxis & 0 & NA & NA & $26 / 30(87 \%)$ & $\begin{array}{l}18 \\
(60 \%)\end{array}$ \\
\hline
\end{tabular}

We offer several observations here. First, the reflective essay provided the richest material for assessing how effectively students had achieved the threshold concepts-possibly because it invited students to both show they understood the concept and reflect on their learning-and it was the last assignment of the semester, which meant that the earliest concepts (social constructionism, privilege and oppression, and intersectionality) had had time to be reinforced throughout the rest of the course even after they were first introduced.

Second, as we discuss in the next section, the concept that gave students the most trouble was intersectionality; the lowest number of students demonstrated achievement of understanding how an intersectional approach undergirds WGS-and that when asked to complete an in-class survey at the end of the semester, very few students could articulate an understanding of the concept in a timed situation and without course resources in front of them (just under a quarter), though a much higher percentage (83\%) were able to explain the concept and its applications in an untimed setting in the context of the whole course and available materials. ${ }^{8}$ Lastly, as we discuss below, the concept that we would consider to 
be the most foundational to an introductory WGS course-social constructionism-was the one students were most able to grasp all across the group of participating students, the multiple assessments, and the course as a whole. We see this as an important piece of information as an instructional takeaway as WGS as a field maps out the extent and importance of new threshold concepts or revises those we have developed.

\section{BARRIERS, BOTTLENECKS, AND MISCONCEPTIONS}

As we set out to analyze students' writing to gain insight into the barriers, misconceptions, and learning roadblocks that they experienced during the semester, we not only kept the concept of liminality in mind to help us consider students' processes of encountering the threshold concepts, but also focused on Meyer and Land's related term, pre-liminal variation, to help us think about the importance of students' starting points when encountering the concepts. Meyer and Land suggest that instructors "can distinguish, in theory at least, between variation in students' 'tacit' understanding (or lack thereof) of a threshold concept" (2005, p. 384). They continue,

We see this situation of what we choose to call pre-liminal variation as a potentially important and useful means of opening up our understanding of why some students will productively negotiate the liminal space and others find difficulty in doing so (2005, p. 384).

In other words, not surprisingly, where students start the semester's learning affects how they will encounter the threshold concepts.

In analyzing students' skills assessments in particular, there was quite a bit of variation in the ease with which they were able to integrate the language of the threshold concepts into their prose. This skill maps most closely to the 'framing and analysis' part of our assessment rubric (see Appendix E), and has to do with whether and how the student used the threshold concept to frame her analysis and demonstrate a feminist epistemological stance. Assessing this skill relates to Meyer and Land's reminder about the discursive nature of threshold concepts. As they write, "The acquisition of transformative concepts, it is argued, brings with it new and empowering forms of expression that in many instances characterise distinctive ways of disciplinary thinking" (2006, p.20). In other words, part of the work of crossing the threshold entails the adoption and use of a specialized language and vocabulary, and the integration of that specialized vocabulary into the rest of one's language repertoire. Because our project design focused exclusively on an analysis of student's written work, it is particularly easy to see this aspect of the nature of threshold concepts; in fact, it would be impossible not to. To hone in on this particular measure of whether the students had crossed the threshold of understanding, we re-read the first skills assessment focusing only on framing and analysis; we deemed seven students to be achieving the learning goal at an advanced level, 15 at a proficient level, four at a competent level, and six at a developing level [see Table 1 above-these numbers are a further breakdown of our finding that 26 of 32 students had crossed the threshold of understanding].

Meyer and Land's assertion about 'distinctive ways of disciplinary thinking' as represented through discipline-specific language gestures toward the potentially empowering effects of acquiring new forms of expression, and certainly there were some students who seemed to experience them in this way. For example, in the reflective essays, a few students described the fact that the threshold concepts provided them with language to name concepts or phenomena about which they had previously only had an intuitive understanding. One student wrote that 
At the beginning of the semester, I was not completely familiar with this term, but as we learned more about it, I realized that it was something that I was aware of in the world around me, but was never able to put a term to it.

Another student reflected, "I think that looking back I knew what all these things were, I just was never able to put words to the ideas." For these students, according to Meyer and Land, "the definition of the concept may thus simply formalise tacit knowledge and experience that the student already feels comfortable with-what we refer to... as the 'underlying game"' (2006, p.29).

By contrast, the students who struggled to use the language of the threshold concept seemed to have a quite different experience, which constituted a barrier to understanding. Meyer and Land go on to acknowledge that for some students, the discursive aspect of threshold concepts may be "a source of troublesomeness, impeding and frustrating further development" (2006, p.21). For students in the developing and competent categories, there was clear evidence of struggle with this aspect of the threshold concept. In some cases this struggle manifested in stilted, awkward integration of the threshold concept and its related terminology, while in other cases there was an over-reliance on quotes and paraphrase from the course materials. One student's thesis is illustrative of the former: "With in this paper I will be discussing three main points, how Axe commercials are sexist against both men and women, discriminating to women, and a stereotypical sex-loving men." Another example of struggling to use the language of the threshold concept comes from a student who opened her essay thusly: "Commercials are very gender biased and very socially gendered constructed." This same student uses the phrase "Another gender social construction I noticed in this commercial ...," and concludes her essay with this observation: "It's amazing to analyze something like this and see all the social constructions of gender." With regard to the latter, this student incorporated language from the assignment prompt in a way that indicated a lack of understanding: "First, the Axe Body Spray advertisement illustrates key concepts about gender norms because body sprays are gendered constructing the factors of masculinity and femininity."

As reported above, six of the 32 students were judged not to have crossed the threshold with regard to the concept of the social construction of gender at the point in the semester when we assessed that concept through the first skills assessment, though an unresolved question in the analysis of this is whether students' difficulty in using disciplinary vocabulary could obscure the level to which they had achieved a command of the concepts. For example, those students, in some way or another, used language in their analyses of the chosen commercial that suggested that they still saw gender as stable and natural, as opposed to socially constructed. One student, for example, wrote that in the commercial,

They demonstrate that woman are clingy the morning after, and have an emotional connection to the other person. On the other hand in this video it shows that men have no emotional connection at all. They want to just live their daily lives and don't want to be pestered by anenight stand.

The student did not use language that demonstrated awareness of the constructedness of these messages.

A common feature, then, of students who did not demonstrate that they had passed the threshold of understanding was the use of the verbs "show," or "demonstrate," as opposed to, say, "portray" or "represent," in their descriptions of what the commercial was doing. One student wrote that "they show that a man cannot enjoy life if there is a girl around." A close reading of these students' essays 
revealed that they sometimes used all four verbs, seemingly interchangeably, which makes it hard to discern whether the students' struggle was merely linguistic, conceptual, or both. This issue of verb usage is another dimension of Meyer and Land's point about the discursive nature of threshold concepts. Therefore, as we evaluated students' achievement of particular threshold concepts, sometimes we struggled to distinguish whether a lack of clarity in student understanding emerged from an actual conceptual weakness or a linguistic immaturity; had we incorporated interviews, think-alouds or focus groups, we could have more directly accessed student insights with other kinds of evidence collection that would have deepened our understanding of the student perspective. And as one of Peter Felten's "Principles of Good Practice in SoTL," (2013) an additional method to partner with students in unpacking their learning could have provided rich additional information that would have helped us answer our research questions.

Students' language choice may be less about deliberately communicating a meaning than it is about facility with the electronic thesaurus; or it simply might reflect very different levels of sophistication in students' respective grasping of the concept which makes in-class or out-of-class interventions more challenging for students at different levels of understanding. Whatever the cause, coming to these realizations through our analysis of our students' work has proven useful in terms of thinking about how we can incorporate these insights into our teaching. One idea for how to help students negotiate this potential barrier or bottleneck around the threshold concept of the social construction of gender is to design a classroom activity in which students read sample student analyses and reflect on the differing meanings conveyed or connoted by the use of different verbs. An activity such as this also supports the idea that there are multiple dimensions of the threshold concepts approach that help make students' learning visible.

\section{Mapping the Challenges of Intersectionality}

Intersectionality seems to be the most challenging threshold concept for students to grasp, because it requires a prior understanding of privilege and oppression in particular. Furthermore, an understanding of privilege and oppression is necessary but not sufficient to lead to understanding of intersectionality. This finding emerged most starkly in our analysis of the surveys administered at the beginning and end of the semester. While it was not surprising that only one out of 34 students (3\%) could provide a definition of intersectionality at the beginning of the semester, it was somewhat less expected that that number rose to only seven out of 29 (24\%) by the end of the semester. This stands out in contrast to the other three threshold concepts as well, especially feminist praxis; none of the students was able to define feminist praxis at the beginning of the semester, but $60 \%$ were able to do so by the end. We also assessed students' understanding of intersectionality in the second skills assessment and in the reflective essay; by these measures a much larger number of students crossed the threshold. More specifically, 21 out of $30(70 \%)$ of students demonstrated an understanding of intersectionality in their second skills assessment, while 25 out of 30 (83\%) did so in their reflective essays. One speculation is that, of the four concepts, intersectionality is the hardest to define/explain in one sentence, perhaps especially when writing by hand on a handout on the fly at the end of a class period. A different way of putting this is to say that some students were able to do an intersectional analysis, but struggled to provide a coherent definition of the concept.

We see this as indicative of more than one challenge: first, when one concept is dependent on a full understanding of a prior one, there's greater risk of students encountering and reproducing misunderstanding (or not having the appropriate foundation for understanding the subsequent, more complex concept). Further, there were different strengths and weaknesses of the two tools we used to 
measure these concepts-the reflective essay gave us a more nuanced and complex glimpse of student learning, because students had more time and discursive space to provide it. However, an on-demand assessment like the final learning survey demands a different level of understanding from students (but provides less time and space to demonstrate it-and rewards students who are quick thinkers, writers, and recallers).

More specifically, students who struggled with the concept of intersectionality often engaged in what Meyer and Land refer to as "mimicry." One student writes, for example, in her reflective essay,

This concept of intersectionality was a little hard for me to comprehend at first so I started to read articles on this topic to better my understanding of intersectionality. The sentence '... has shown how the experience of gender differs by race, class and other dimensions of inequality' in the book. . helped me to better comprehend this concept.

As the student continues, however, it is apparent that she has not in fact understood the quote she provides. Her takeaway is that intersectionality "causes harm to women," and that "Knowing this without a doubt I will stand up for women in situations involving intersectionality.” The student's struggle to understand the concept is shown by the fact that she resorts to a quote rather than attempting to explain the concept in her own words. Her struggle is perhaps even shown in her excerpting of the quote, in that she has trouble integrating the author's words with her own. But rather than merely trying to give the instructor what they want, we see in this passage "both attempts at understanding and troubled misunderstanding, or limited understanding" which supports the idea that mimicry is "not merely intention to reproduce information in a given form" (Meyer and Land, 2006, p.24). By contrast, students who clearly grasped the threshold concept of intersectionality defined it with reference and in relation to the concepts of privilege and oppression. One student defined intersectionality as "different facets of people that are classified by gender, sexual orientation, race, class, gender, status, etc., that measure likelihood to experience privilege and oppression." Another student wrote that "intersectionality is all about the connection of the different -isms."

One final point about students' struggles to cross the threshold concerns the fact that students' crossing of the threshold into understanding often "does not happen in a straight line but instead in iterative and recursive stages” (Adler-Kassner, Majewski, \& Koshnick, 2012, p.2). In reading our students' essays, there were several moments where we were reminded of Land, Rattray, and Vivian's assertion that "learning in the liminal state is sometimes experienced as oscillative, as the changed perspective slips in and out of focus and eludes the learner's grasp” (2014, p.201). This framework is helpful in that it provides a way to think about student learning that gets away from an all-or-nothing approach; instead, it suggests that "temporary regression to earlier status" (Meyer \& Land, 2006, p.24) can be a part of the longer arc toward crossing the threshold. Our findings support the notion that students' learning journeys reflect this complex movement between developing and proficient or advanced commands of the threshold concepts.

A good example of this oscillation can be seen in one student's, Rhonda's, second skills assessment, an assignment focused on discussing work-life balance in relation to the first three threshold concepts. In her essay, Rhonda demonstrates a strong grasp of the concept of intersectionality by discussing how workplace issues are experienced differently depending on one's race, sexuality, gender identity, and class. Her final point is a consideration of workplace issues faced by a trans man. She writes: 
If you do not identify as male or female, your opinions are usually swept under the rug as to not cause confusion or disruption in the steady flow of American life. But it is something that needs to be pulled out from under the rug because it has a very large impact on how society responds to you. For my example I will use tech giant Google again. Google offers six weeks of paid leave for fathers and up to 18 weeks of paid leave for mothers. What happens when a transgender man is employed at Google and his wife is having a baby? Does the man get the allotted six weeks off because he considers himself male or, because his birth certificate says "female" does he get up to 18 weeks off? Questions and situations like this offer insight into the world marginalized groups live in. It is time that the United States realizes and respects marginalized groups' needs.

While we were pleased with this student's grasp of the concept of intersectionality, we were confounded to see her mistakenly offer this extended example under the heading of sexual identity, rather than gender identity. Without further information from the student, our analysis of what's going on in this passage is speculative, but one possibility is that her mental focus was more trained on what was the newest threshold concept to her in that moment, which resulted in being less careful with the previously-learned concept. Another possibility is that she experienced difficulty bringing the earlier concept to bear on the newer concept, or put another way, of integrating the two together. A third interpretation might be that Rhonda is still developing the disciplinary language to accurately distinguish between sexuality, sexual identity, and gender identity, and conflated these terms as she developed her example.

Understanding the link between the two threshold concepts appears to make the critical difference for students in grasping intersectionality. Students who struggled with the concept did not seem to grasp those connections. This was a teaching "a-ha" moment for both of us; in future semesters, we both plan to make stronger connections between the concepts of privilege/oppression and intersectionality. Our suggestion is to foreground the connection when privilege and oppression are introduced, then again throughout the section of the course focused on intersectionality. We would also argue that it is not a one-way street; that is, even though it appears that intersectionality is the harder of the two concepts to grasp, it is not just that emphasizing the connection aids in understanding intersectionality. Rather, once a student understands intersectionality (at least in part through grasping its connection to privilege and oppression), his/her understanding of privilege and oppression may deepen as well. As Land, Rattray, and Vivian point out, "The addition of a new concept to a learner's collection can also affect the understanding of other concepts in that collection with the result that over time the whole collection develops and changes" (2014, p. 208). This finding resonates with Meyer and Land's assertion that threshold concepts are integrative, in that once the threshold is crossed, the "previously hidden interrelatedness" of the concepts is exposed. As one student wrote, "The idea of intersectionality kind of ties all of our learning together in the way that it is by definition the intersections between different forms of systems of oppression.”

\section{ADDITIONAL QUESTIONS AND CONCLUSIONS}

As we reflect on the observations we made by looking at student learning systematically over the course of a semester, there are opportunities where our research design could have been adjusted to get at some of the questions that emerged during analysis. Evaluating the effectiveness of the threshold concept model-perhaps reflective of any kind of assessment of student learning-is complicated by the material reality that students' grasp of a concept may not be clear from one assessment to another; variation in topic, point in the semester, and efforts by students can make it difficult to fully and 
accurately assess whether students have or have not achieved understanding of the threshold concept. While this is a limitation more broadly in any kind of assessment of student learning, we are convinced that using interviews, think-alouds or focus groups would have helped clarify some of the ambiguity we encountered in our analysis of our students' writing, and any future projects will include one or more of these methods.

In our own teaching, we plan to incorporate our findings into our courses and continue the process of assessing and reflecting on what works and what doesn't, for whom, and why. We are particularly eager to think about where and how to emphasize the interrelated nature of the threshold concepts, especially privilege and oppression and intersectionality. In this article we primarily focused on the first two of our four research questions; future publication could take up the other two questions. The concept of pre-liminal variation seems a promising lens through which to further explore student learning in the WGS classroom as we consider the wide variation in students' prior learning about gender and feminism, the vastly different experiences and identities they bring with them into the classroom, and the attendant dispositional attitudes that they bring to their learning.

We also want to close by advocating for additional work using a systematic method (in ways that are appropriate for WGS) to build a firmer foundation for teaching and learning in the field. SoTL work can be adapted to fulfill feminist purposes by blending systematic methods with recognition of subjectivity, standpoint theory, and the non-perfectly-comparable nature of specific courses, students, and sections. We believe that progress that moves pedagogical knowledge in WGS forward requires formal inquiry that both frames teaching and learning research questions and honors, through mixed methods, student voices in the process of tracing intellectual and personal growth.

Holly Hassel is a Professor of English and Gender, Sexuality, and Women's Studies at the University of Wisconsin Marathon County, USA.

Christie Launius is Associate Professor and Director of Women's and Gender Studies at the University of Wisconsin-Oshkosh, USA. They are the co-authors of the introductory textbook Threshold Concepts in Women's and Gender Studies: Ways of Seeing, Thinking, and Knowing.

\section{NOTES}

1. While the co-authors ultimately decided on the four threshold concepts, their decision was the culmination of the aforementioned ongoing conversations with a large number of colleagues across the state. Twenty-four instructors were surveyed about the learning outcomes, vocabulary, and important concepts they focused on in their introductory courses. This survey generated a list of over 70 items; subsequently, the co-authors used these survey results as the starting point of an ongoing discussion that spanned more than a year and focused on identifying those items that met the criteria of being a threshold concept.

2. The social construction of gender refers to the idea that gender is distinct from sex and not immutable, with a particular focus on mapping out how, where, and to what effect gender is socially constructed. As a threshold concept, privilege and oppression refers to systems of structural inequality that confer privilege on some groups while marginalizing others. Intersectionality focuses on the ways that systems of privilege and oppression intersect. And finally, feminist praxis refers to the practice of employing and implementing feminist knowledge in an effort to challenge intersecting systems of inequality.

3. See Christie Launius and Holly Hassel. Coverage, Content, Concepts: Textbooks for Courses Introductory Courses in Women's and Gender Studies. Rev. of Eighteen Textbooks. Feminist Collections. A Quarterly of Women's Studies Resources.

4. Two exceptions are a 2011 IJSotL article on the threshold concept "patriarchy as a system" and 
Simoes and Gray's study of information literacy and service-learning projects in introductory women's studies courses (2008).

5. Indeed, the process of writing this essay has caused us to consider the possibility of a fifth threshold concept having to do with the centrality of self-reflection and critical reflexivity in the field.

6. It should be noted that at various points in the semester, not all students completed and submitted all pieces of work assigned.

7. Because we teach on different campuses and live in different cities, our project was greatly aided by the use of technology. Our work sessions were conducted via Skype, and we uploaded all of the related documents and spreadsheets to Google Docs.

8. We should note that the survey was a much less precise and extensive tool for showcasing student learning-a few brief questions, completed in class in the last week of the semester-while the reflective essay was completed out of class and students had extensive lead time to complete the essay before it was assessed.

\section{REFERENCES}

Adler-Kassner, L., \& Wardle. E. (2012). Naming what we know: Threshold concepts of writing studies. Boulder, CO: Utah State University Press.

Adler-Kassner, L., Majewski, J. \& Koshnick, D. (2012). The value of troublesome knowledge: Transfer and threshold concepts in writing and history. Composition Forum, 26.

Ambrose, S., Bridges, M., DiPietro, M., Lovett, M., Norman, M., \& Mayer, R. (2010). How learning works: Seven research-based principles for smart teaching. San Francisco, CA: Jossey-Bass.

Calder, L. (2006). Uncoverage: Toward a signature pedagogy for the history survey. The Journal of American History, 92, 1358-1370.

Felten, P. (2013). Principles of good practice in SoTL. Teaching \& Learning Inquiry: The ISSOTL Journal, 1(1), 121125.

Hassel, H., \& Nelson, N. (2012). A signature feminist pedagogy: Connection and transformation in Women's Studies. In N. Chick, A. Haynie, and R. Gurung (Eds)., Exploring more signature pedagogies: Approaches to teaching disciplinary habits of mind. (pp. 145-155). Sterling, VA: Stylus.

Haswell, R. (2005). NCTE/CCCC's recent war on scholarship. Written Communication, 22, 198-223.

Hofer, A., Townsend L., \& Brunetti, K. (2012). Troublesome concepts and information literacy: Investigating threshold concepts for IL instruction. Libraries and the Academy, 12(4), 387-405.

Humphrey, R., \& Simpson, B. (2012). Writes of passage: Writing up qualitative data as a threshold concept in doctoral research. Teaching in Higher Education, 17(6), 735-746.

Hutchings, P. (Eds.). (2000). Opening lines: Approaches to the scholarship of teaching and learning. Menlo Park, CA: The Carnegie Foundation for the Advancement of Teaching.

Land, R, Rattray, J., \& Vivian, P. (2014). Learning in the liminal space: A semiotic approach to threshold concepts. Higher Education, 67, 199-217.

Launius, C., \& Hassel, H. (2013). Coverage, content, concepts: Textbooks for introductory courses in women's and gender studies. Rev. of Eighteen Textbooks. Feminist Collections. A Quarterly of Women's Studies Resources. 34(1, Winter 2013). 8-16.

Launius, C., \& Hassel, H. (2015). Threshold concepts in Women's and Gender Studies: Ways of thinking, seeing, and knowing. New York, NY: Routledge

Levin, A. (2007) Questions for a new century: Women's studies and integrative learning. A report to the national women's studies association. National Women's Studies Association, College Park, MD: NWSA, 2007.

Meyer, J. H.F., \& Land, R. (2005). Threshold concepts and troublesome knowledge: Epistemological considerations and a conceptual framework for teaching and learning. Higher Education, 49, 373-388.

Meyer, J.H.F., \& Land, R. (2006). Threshold concepts: Issues of liminality. In J. H.F. Meyer and R. Land. (Eds), Overcoming barriers to student understanding: Threshold concepts and troublesome knowledge. (pp. 19-32). New York, NY: Routledge.

Pace, D., \& Middendorf, J., Eds. (2004). Decoding the disciplines: Helping students learning disciplinary ways of thinking. San Francisco, CA: Jossey-Bass.

Simoes, S., \& Gray, S. (2008). Combining academic service-learning and information literacy: A new framework for an introductory women's studies course. The Scholarship of Teaching and Learning at EMU, 2(8) 
Solnit, R. (2013, January). A rape a minute, a thousand corpses a year. Mother Jones. Retrieved from http://motherjones.com/politics/2013/01/rape-and-violence-against-women-crisis/

\begin{abstract}
(C) Copyright for the content of articles published in Teaching \& Learning Inquiry resides with the authors, and copyright for the publication layout resides with the journal. These copyright holders have agreed that this article should be available on open access under a Creative Commons Attribution License 4.0 International (https://creativecommons.org/licenses/by/4.0). The only constraint on reproduction and distribution, and the only role for copyright in this domain, should be to give authors control over the integrity of their work and the right to be properly acknowledged and cited, and to cite Teaching \& Learning Inquiry as the original place of publication. Readers are free to share these materials - as long as appropriate credit is given, a link to the license is provided, and any changes are indicated.
\end{abstract}

